\title{
Mechanical Properties of Particleboard Made from Rice
}

\section{Husk}

\author{
Takao Ota $^{1 *}$ and Tomoya Okamoto ${ }^{2}$ \\ 1. Innovation Center for Cooperative Research, National Institute of Technology, Toyama College, Toyama 939-8630, Japan \\ 2. Department of Mechanical Engineering, National Institute of Technology, Toyama College, Toyama 939-8630, Japan
}

\begin{abstract}
This study was conducted to develop particleboard formed from rice husk particles by hot pressing with a PVA (Polyvinyl alcohol) binder. A preform was prepared using mixed rice husk particles, PVA powder, and purified water. The rice husk particle and the PVA binder contents were fixed at 80:20. The rice husk particleboard was fabricated using the hot pressing method. The flexural strength and modulus of resulting particleboard were investigated. Results showed that mainly, the rice husk particleboard satisfied the reference flexural strength (flexural strength is $13 \mathrm{MPa}$ or more) of base type 13 particleboard according to JIS A 5908 . However, it exceeded the reference density even for flexural modulus higher than $2.5 \mathrm{GPa}$.
\end{abstract}

Key words: Agricultural by-product, rice husk, PVA (Polyvinyl alcohol) resin, particleboard, mechanical properties.

\section{Introduction}

Particleboard, a wood-based board product, is manufactured mainly using wood particles and binder. Recently, the use of alternative resources as a substitute for wood raw materials has increased in the particleboard industry because of the depletion of forest resources. Studies of particleboard using wood residues and agricultural by-products have examined wheat straw [1], rice straws, husks [2, 3], bagasse [4], walnut/almond shells [5], palm trunks [6].

Rice is a familiar food for Japanese people. According to the MAFF (Ministry of Agriculture, Forestry and Fisheries), Japan produced 8.6 million tons of rice in 2013 [7]. Rice straws and rice husks, as agricultural by-products, are obtained after every year's rice harvest. They are annually renewable materials available in abundant volume throughout the world. Rice straw is useful as fodder for livestock and plowing-in. However, the uses of rice husks are few. Most rice husks are burned. Recently, rice husks might not even be burned in many prefectures in

*Corresponding author: Takao Ota, associate professor, research fields: strength of material, composite materials and interface engineering.
Japan because of environmental regulations.

Rice husks contain approximately $20 \%$ of silica. The rice husk outer surface is rougher than the inner surface. Silica exists on the outer surface of rice husks in the form of silicon-cellulose membrane [8]. Therefore, it may be expected that rice husk particleboards have higher strength and stiffness than those of wood-based particleboard.

This study was conducted to develop rice husk particleboard, which satisfies the standard of type 13 particleboard according to JIS A 5908 [9]. Furthermore, the mechanical properties of rice husk particleboard using PVA (Polyvinyl alcohol) binder were investigated to explore the potential of rice husk as a possible raw material for non-wood bio-based particleboard.

\section{Experimental}

\subsection{Materials}

PVA powder (V-S20; Japan Vam \& Poval Co. Ltd., Japan), which is fully hydrolyzed type, was used as binder. The degree of PVA powder hydrolysis is 99.0 mol\% or higher. Purified water was used as solvent for PVA powder. Rice husks were supplied by a 
farmer who manages farms in Toyama city. Rice husks were ground for 2 min using a mill (SM-1; AS One Corp., Japan). They were then dried in a drying oven (EPN-115, Kosumosu; Isuzu Seisakusho Co. Ltd., Japan) for $24 \mathrm{~h}$ at $80^{\circ} \mathrm{C}$.

\subsection{Particleboard Manufacture}

To facilitate the particleboard molding with a hot pressing machine, a preform was prepared by mixing the rice husk particles, the PVA powder, and the purified water. The rice husk particles and the PVA powder contents were fixed at an 80:20 mass ratio. Fig. 1 portrays a mold apparatus made of A5052. Fig. 2 shows a cross-sectional view of the mold apparatus, which includes a pair of convex upper and lower dies, forming a mold space within the apparatus by enclosing the upper convex die with spacers and by matching the convex surface of the dies. The particleboard was fabricated using a hot pressing machine (AH-2003; AS One Corp., Japan) after charging the mold with the preform to produce a $90 \times 90 \times 5 \mathrm{~mm}^{3}$ panel. To control the apparent density of the particleboard, the amounts of preforms were 30,40 and $50 \mathrm{~g}$. The molding temperatures, pressing times and molding pressures were, respectively, $180^{\circ} \mathrm{C}, 10 \mathrm{~min}$ and $10,20,30$ and $40 \mathrm{MPa}$.

\subsection{Specimen Preparation}

The particleboard mass, which was dried in a drying oven at $80^{\circ} \mathrm{C}$, was measured every 2 min using a precision balance (Adventurer SL AS313; Ohaus Corp., USA) to ascertain the optimum particleboard drying time. Fig. 3 shows the relation between mass change and drying time. This result demonstrates that the mass change is slight after $8 \mathrm{~h}$ drying time. Then the particleboard was dried in a drying oven (EPM-1158; Soyokaze, Isuzu Seisakusho Co. Ltd., Japan) for $8 \mathrm{~h}$ at $80^{\circ} \mathrm{C}$.

\subsection{Mechanical Testing}

A three-point flexural test was conducted using a universal testing machine (Ez-graph; Shimadzu Corp., Japan) at room temperature to evaluate the particleboard mechanical properties. A flexural test specimen was cut from the particleboard using a hand saw. The specimen dimensions were $15 \times 60 \times 5 \mathrm{~mm}^{3}$. The dimensional accuracy was $\pm 0.3 \mathrm{~mm}$. Flexural tests were performed with $1.0 \mathrm{~mm} / \mathrm{min}$ cross-head speed and $40 \mathrm{~mm}$ span length.

\section{Results and Discussion}

\subsection{Effects of Preform Amount}

Fig. 4 presents mechanical properties (flexural strength and flexural modulus) of the particleboard with

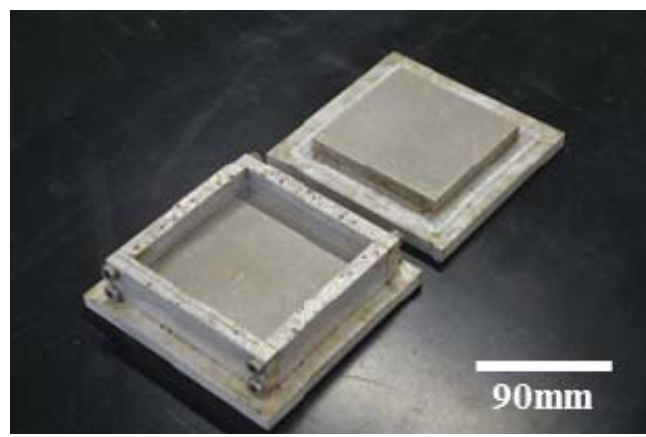

Fig. 1 Appearance of mold apparatus.

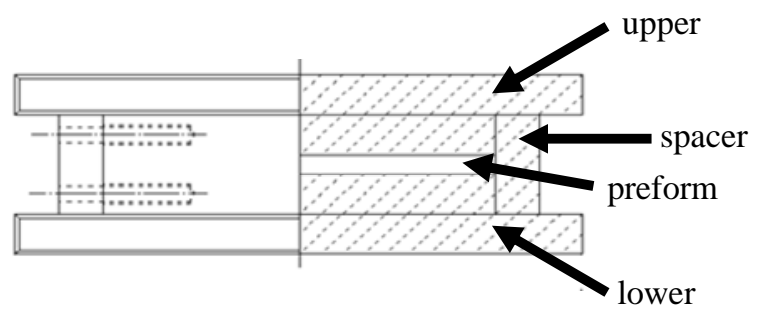

Fig. 2 Cross-sectional view of mold apparatus.

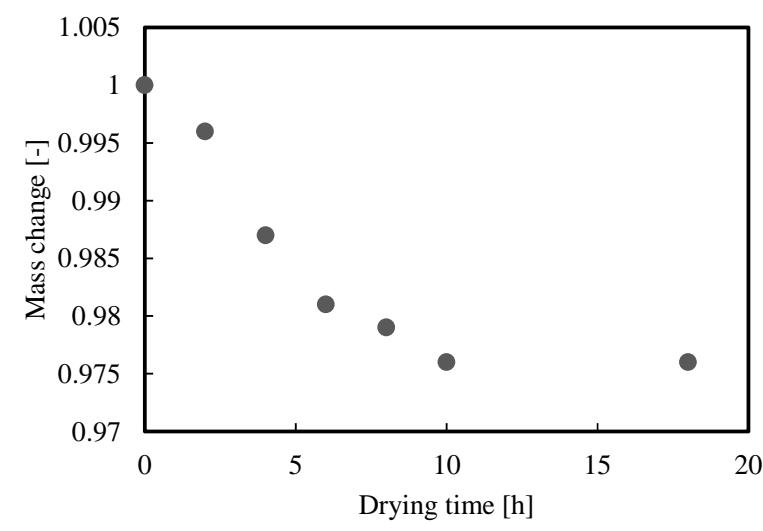

Fig. 3 Relation between mass change and drying time. 


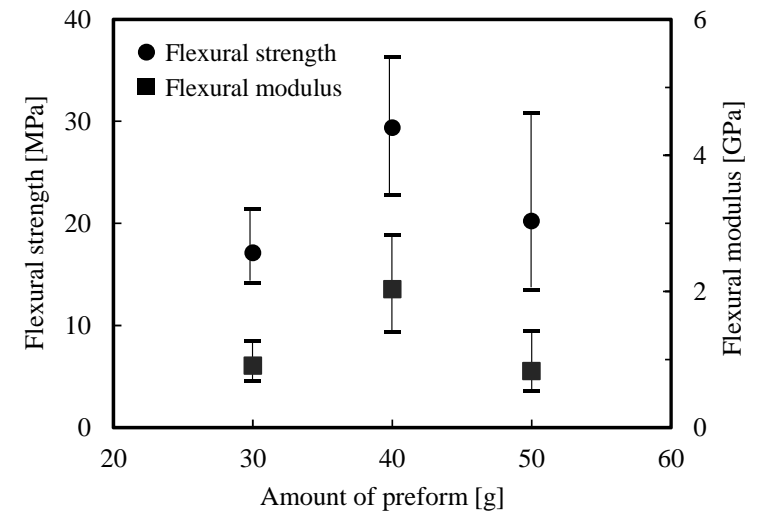

Fig. 4 Mechanical properties of particleboard with respect to the preform amount.

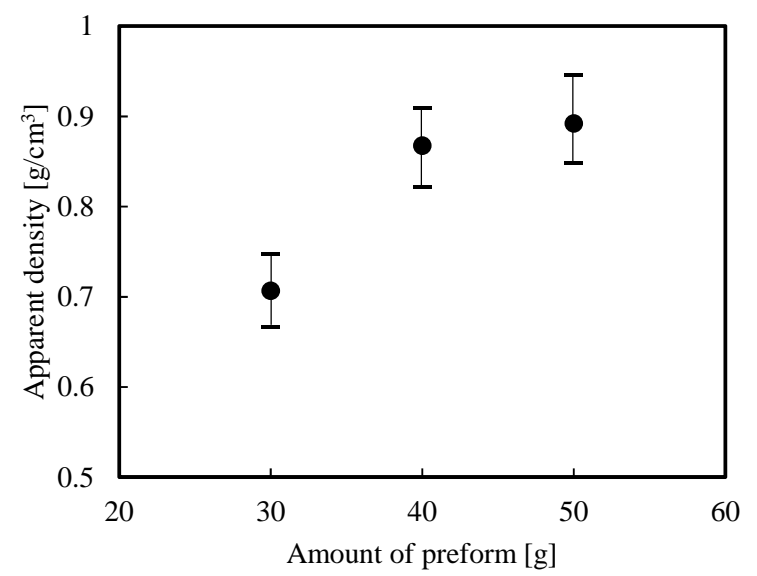

Fig. 5 Variation of apparent density of particleboard with respect to the preform amount.

respect to the amount of preform to assess the variation of the apparent density of the particleboard.

To fabricate the particleboard, the molding pressure was fixed at $10 \mathrm{MPa}$. The flexural strength and flexural modulus increase concomitantly with increasing the preform amount. The particleboard fabricated using the type $40 \mathrm{~g}$ preform shows a peak flexural strength and a peak flexural modulus. The respective peak flexural strength and flexural modulus values are 29.4 MPa and 2.03 GPa. However, results show that the flexural strength and flexural modulus decrease with the rise of the amount of the preform above 40 g. Fig. 5 presents the variation of the apparent density of the particleboard with respect to the preform amount. This result shows that the apparent density increases concomitantly with increasing amount of the preform, whereas the apparent densities of particleboards, which are fabricated by the amount of the preform above $40 \mathrm{~g}$, are almost identical. Figs. 6a-6c show cross-sectional views of the rice husk particleboards fabricated with different amounts of the preform. These figures show that the pore amounts in the particleboard decrease concomitantly with increasing amount of the preform (Figs. 6a and 6b). Consequently, results show that the mechanical properties of the particleboard decrease concomitantly with increasing pore amounts in the particleboard because pores become origins of fracture in the particleboard. In contrast, in the specimen (preform type 50 g) depicted in Fig. 6c, a large crack is visible at the neutral axis in the particleboard. This preform, i.e., preform type $50 \mathrm{~g}$, has more moisture than the others. The particleboard fabricated by hot-pressing using this preform is particularly susceptible to steam. Moreover, it is difficult to release the steam from the mold because a mold space is formed within the mold apparatus by enclosing the upper convex die with spacers and by matching the convex surface of the dies. Consequently, the steam pressure in the mold space is increased, the particleboard expands because of steam pressure in the mold space. Therefore, cracks occur in the particleboard as depicted in Fig. 6c.

\subsection{Effects of Purified Water and PVA Mixing Ratio}

The purified water used for this study is the solvent for the PVA powder. Therefore, we clarified the effect of the mixing ratio of the purified water and the PVA powder on the particleboard mechanical properties. For this study, the purified water and the PVA powder contents, which were 70:30 (wt.\%), 60:40 (wt.\% ), and 50:50 (wt.\%), were prepared. The amounts of the preform and the molding pressure were fixed respectively at $40 \mathrm{~g}$ and $10 \mathrm{MPa}$. Fig. 7 shows the mechanical properties (flexural strength and flexural modulus) of the particleboard with respect to the PVA content. The flexural strength and flexural modulus decrease concomitantly with increasing PVA contents. 


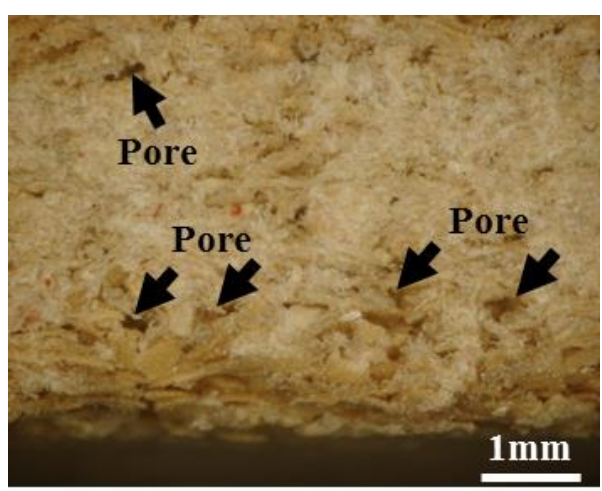

(a) $30 \mathrm{~g}$

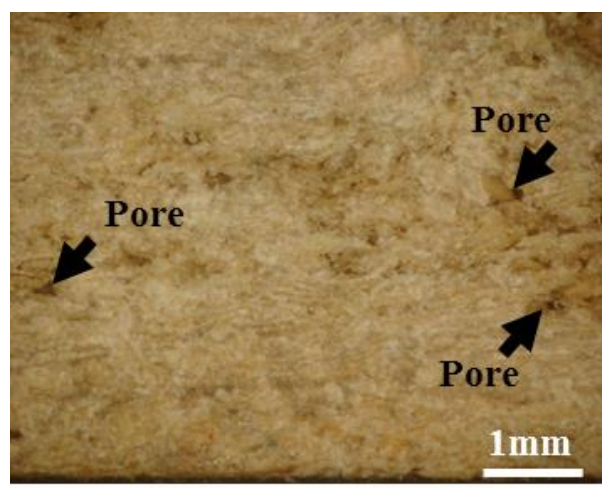

(b) $40 \mathrm{~g}$

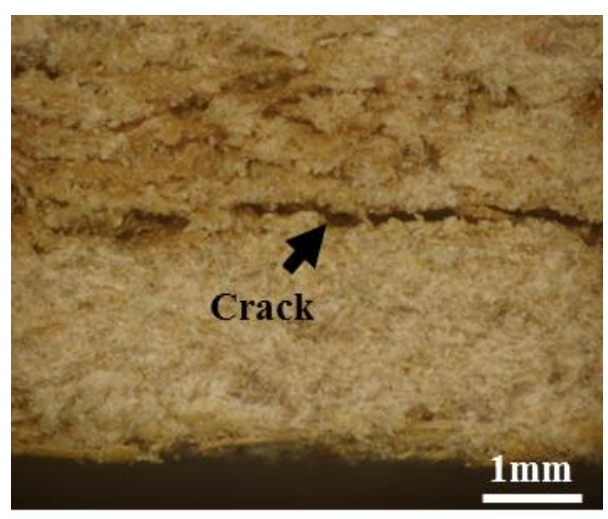

(c) $50 \mathrm{~g}$

Fig. 6 Cross-section views of rice husk particleboard.

The average flexural strength and flexural modulus values decrease respectively from 29.4 MPa to 16.5 $\mathrm{MPa}$ and from $2.03 \mathrm{GPa}$ to $0.94 \mathrm{GPa}$. Fig. 8 portray flat surface views of the particleboard fabricated with different PVA contents. In the specimen (PVA 30 wt.\%) presented in Fig. 8a, PVA film is found on the particleboard surface, indicating that the binder was impregnated among rice husk particles. In contrast, in the specimens (PVA 40 wt.\% and PVA 50 wt.\%) shown

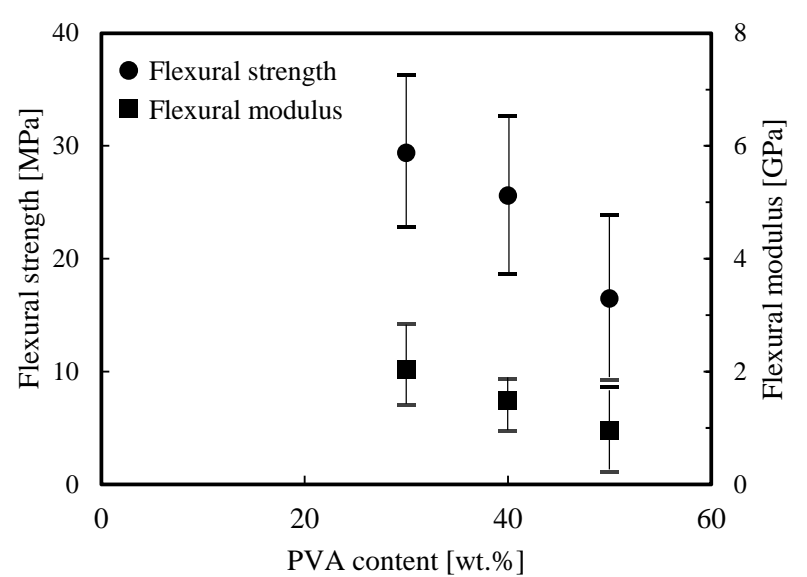

Fig. 7 Mechanical properties of particleboard with respect to PVA contents.

in Figs. 8b and 8c, exposure of the rice husk is visible on the particleboard surface. This result shows that the binder had difficulty impregnating interstices among the rice husk particles: it was difficult to hydrolyze because of the small amount of purified water. Therefore, it is important to control the amount of purified water, i.e., the binder viscosity, and to produce a strong bond among rice husk particles to improve particleboard mechanical properties.

\subsection{Effects of Molding Pressure}

Molding pressure is an important parameter to assess changes of PVA impregnation among particles and the change of apparent density of particleboard. Therefore, we investigated the effects of molding pressure on the particleboard mechanical properties. The amount of the preform and the PVA content were fixed respectively at $40 \mathrm{~g}$ and $30 \mathrm{wt} . \%$. The flexural strength and flexural modulus of the rice husk particleboard with respect to the molding pressure are shown in Fig. 9. Test results show that the flexural strength and flexural modulus increase concomitantly with increasing molding pressure. The peak flexural strength and flexural modulus values are, respectively, 41.4 MPa and 3.02 GPa. The flexural strength and flexural modulus fabricated by the condition of the molding pressure $40 \mathrm{MPa}$ are almost identical to those fabricated by the condition of the molding pressure 30 MPa. Fig. 10 presents a relation between the apparent 


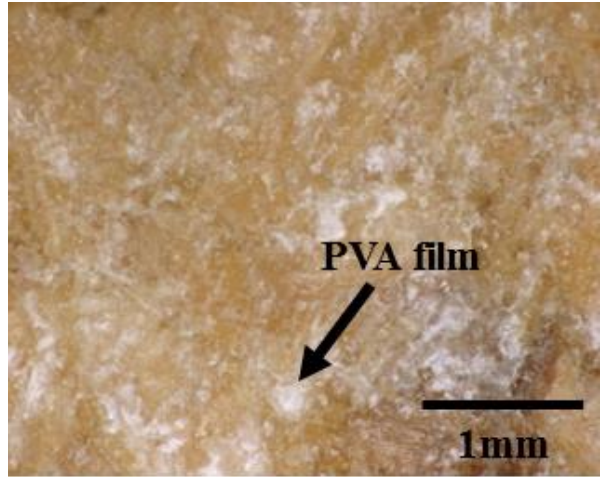

(a) PVA $30 \mathrm{wt} \%$

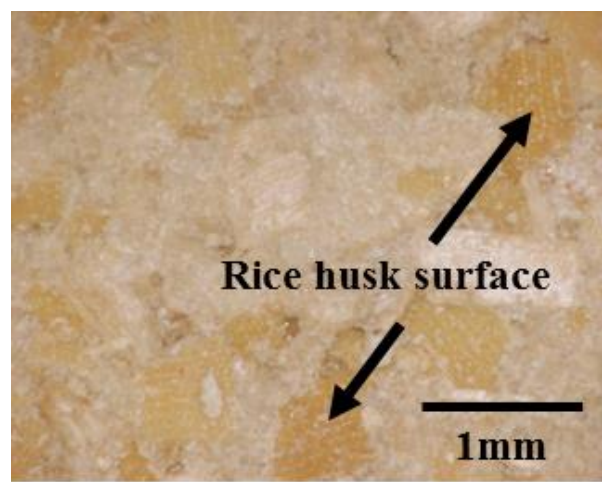

(b) PVA 40 wt. $\%$

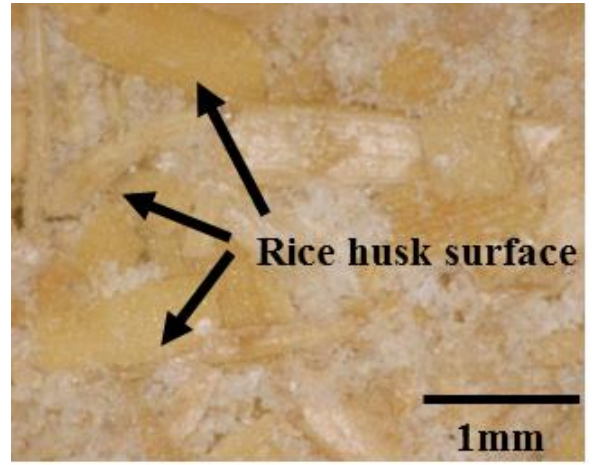

(c) PVA 50 wt. $\%$

Fig. 8 Flat surface views of rice husk particleboard.

particleboard density and the molding pressure. Results show that the apparent density of the particleboard fabricated with conditions of molding pressure $20 \mathrm{MPa}$ is higher than that of the particleboard fabricated with moulding pressure of $10 \mathrm{MPa}$. However, the apparent densities do not differ even if the moulding pressure becomes higher than $20 \mathrm{MPa}$. Fig. 11 shows flat surfaces of the particleboard fabricated with different molding pressure conditions. In the specimen (10 $\mathrm{MPa})$ presented in Fig. 11a, gaps are visible among the rice husk particles, indicating that the spread of the binder is insufficient. In contrast, in the specimens (20 MPa, $30 \mathrm{MPa}$, and $40 \mathrm{MPa}$ ) shown in Figs. 11b-11d, PVA firm film is visible on the particleboard surface, reflecting that the spread of the binder is greater with increasing molding pressure and that particles are bonded strongly. Therefore, we consider that it is important to fabricate the PVA film on the surface of the particleboard to improve the mechanical properties of the particleboard because the maximum tensile stress occurs at the upper surface on the particleboard, as presented in Fig. 12.

\subsection{Effects of Apparent Density}

Figs. 13 and 14 portray the relation between the

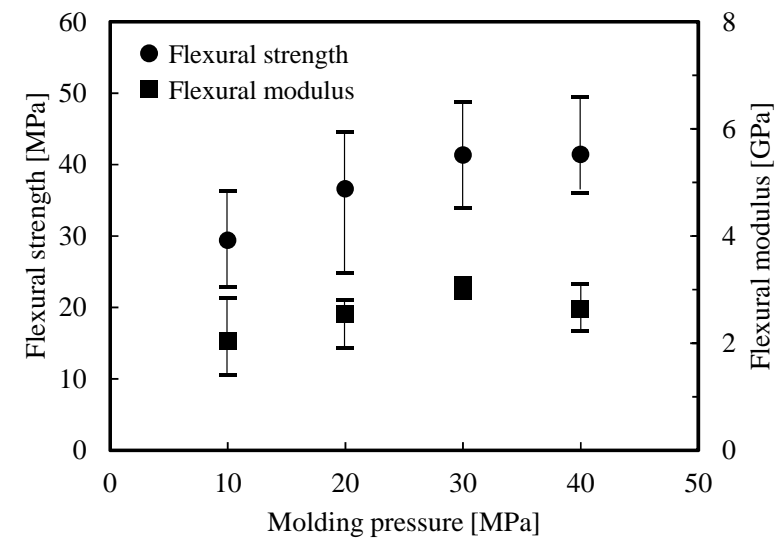

Fig. 9 Mechanical properties of particleboard with respect to molding pressure.

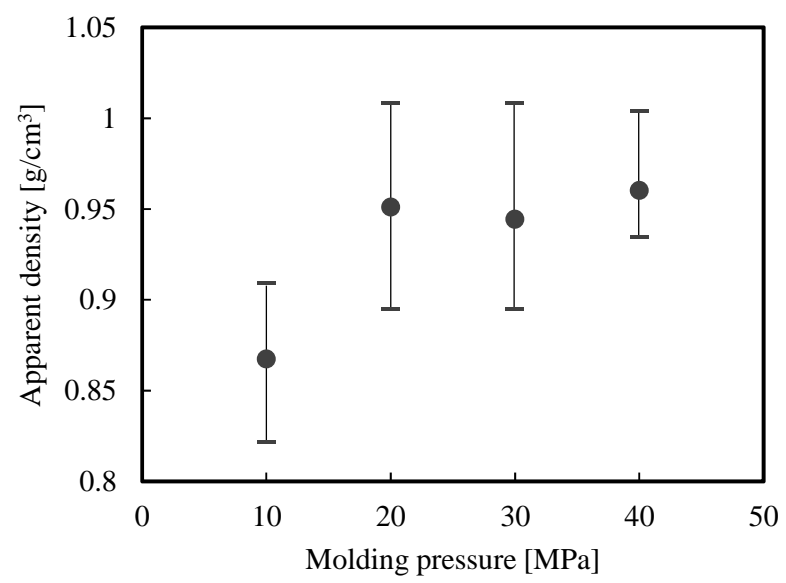

Fig. 10 Variation of apparent density of particleboard with respect to molding pressure. 


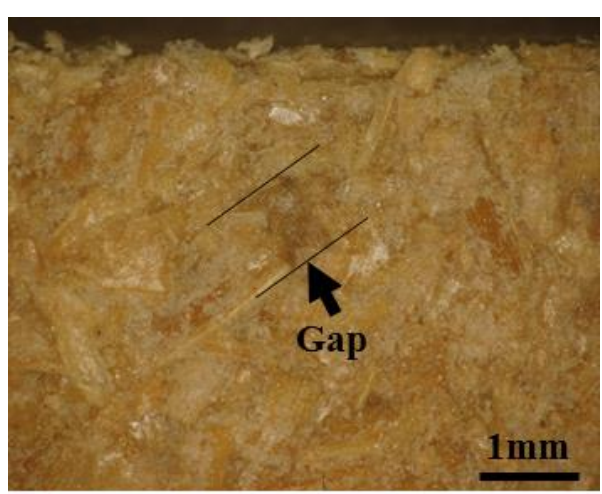

(a) $10 \mathrm{MPa}$

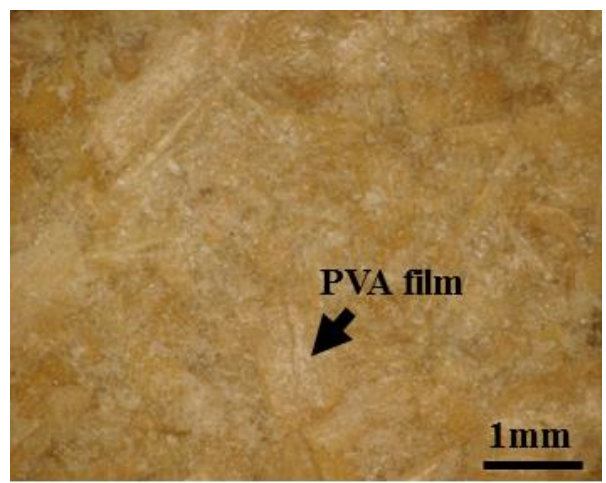

(b) $20 \mathrm{MPa}$

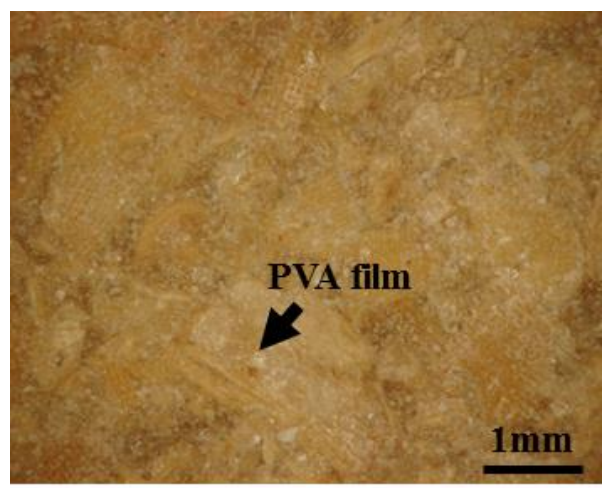

(c) $30 \mathrm{MPa}$

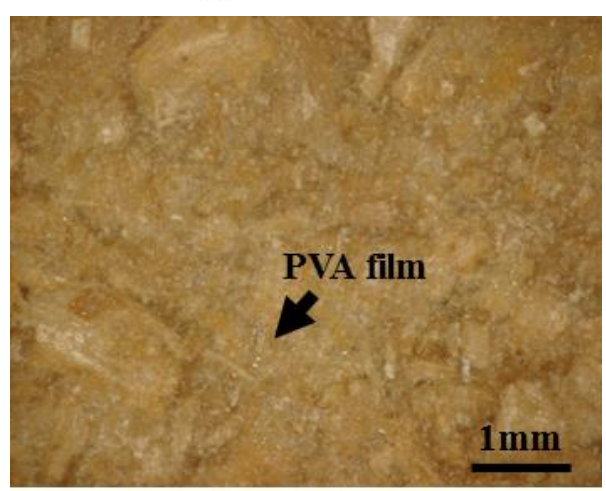

(d) $40 \mathrm{MPa}$

Fig. 11 Flat surface views of rice husk particleboard.

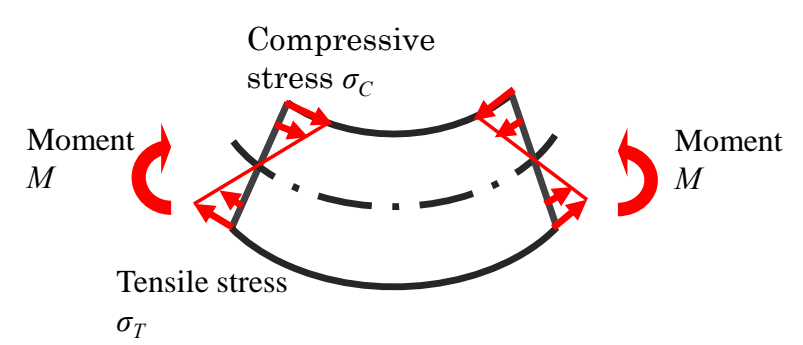

Fig. 12 Stress distribution of rice husk particleboard.

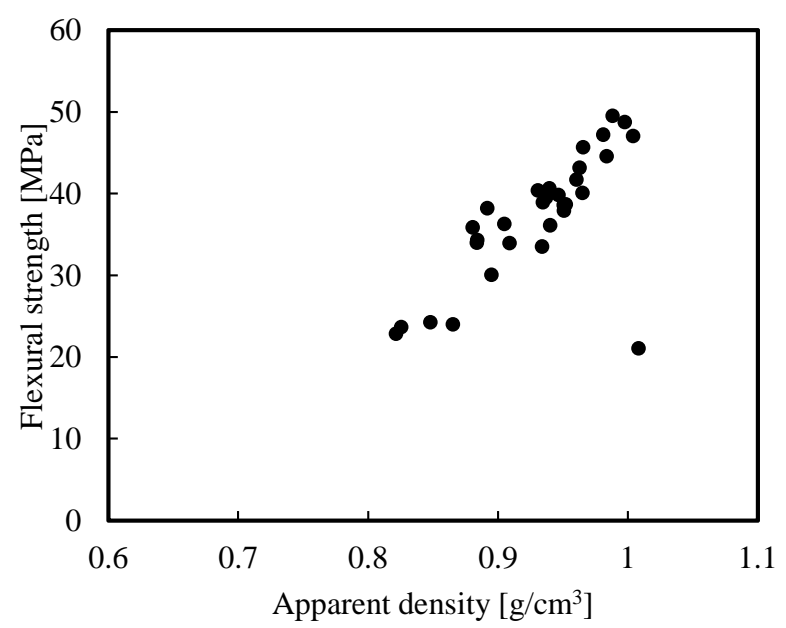

Fig. 13 Relation between flexural strength and apparent density.

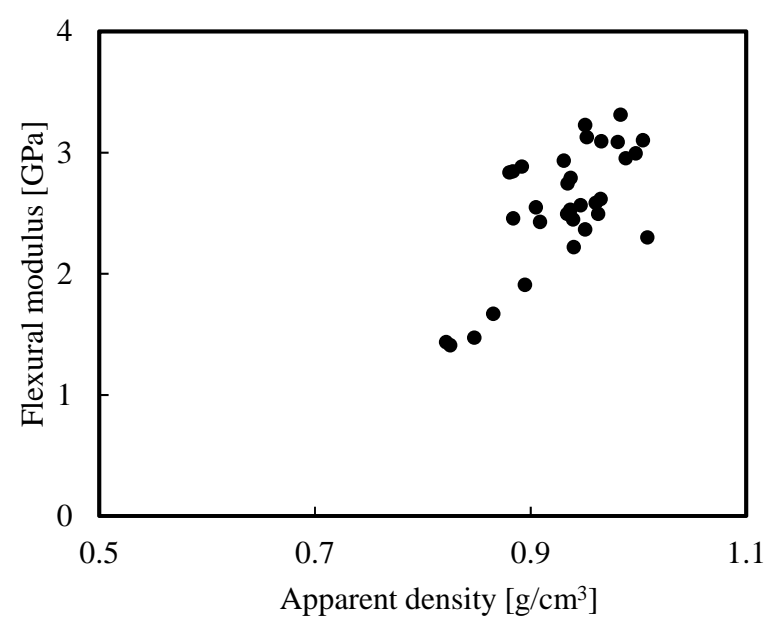

Fig. 14 Relation between flexural modulus and apparent density.

apparent density and the mechanical properties of the particleboard. These figures illustrate that the apparent density and the mechanical properties have strong correlation, indicating that the flexural strength and flexural modulus of the particleboard increase concomitantly with increase of the apparent of the particleboard. We have strived to develop a rice husk 
particleboard that satisfies the type 13 particleboard standard according to JIS A 5908 [9]. The reference flexural strength, the reference flexural modulus, and the reference density of type 13 particleboard are, respectively, higher than $13 \mathrm{MPa}$, higher than $2.5 \mathrm{GPa}$ and less than $0.9 \mathrm{~g} / \mathrm{cm}^{3}$ [9]. Results show that the developed particleboard satisfies the reference flexural strength of type 13 particleboard. However, particleboard of the apparent density, which is less than $0.9 \mathrm{~g} / \mathrm{cm}^{3}$, does not satisfy the reference flexural modulus of type 13 particleboard. In fact, the developed particleboard exceeded the reference density of type 13 particleboard even though the flexural modulus of the particleboard is higher than $2.5 \mathrm{GPa}$. This problem will be clarified and reported further in our future work.

\section{Conclusions}

This study investigated the mechanical properties of particleboard made from milled rice husk particle and PVA resin to investigate the potential for the use of rice husks as a raw material for non-wood bio-based particleboard. Summarized results and remarks are presented below:

(1) Particleboard produced using preform type $40 \mathrm{~g}$ had peak flexural strength and peak flexural modulus;

(2) Particleboard fabricated using the preform type $50 \mathrm{~g}$ expanded because of steam pressure in the mold space. Cracking occurs at the neutral axis;

(3) The flexural strength and flexural modulus decreased concomitantly with increasing PVA contents. The average flexural strength and flexural modulus values decreased respectively from 29.4 to 16.5 MPa and from 2.03 to $0.94 \mathrm{GPa}$;

(4) The spread of the binder is greater with increasing molding pressure; PVA film was formed on the particleboard surface. The PVA film formation enhanced the particleboard mechanical properties.
(5) The apparent density and the mechanical properties show strong correlation, indicating that the flexural strength and flexural modulus of the particleboard increase concomitantly with increasing apparent density of the particleboard;

(6) The developed particleboard satisfied the reference flexural strength of type 13 particleboard. However, the particleboard of the apparent density, which is less than $0.9 \mathrm{~g} / \mathrm{cm}^{3}$, did not satisfy the reference flexural modulus of type 13 particleboard.

\section{References}

[1] Cheng, E., Sun, X. and Karr, G. S. 2004. "Adhesive Properties of Modified Soybean Flour Wheat Straw Particleboard." Composites Part A 35 (3): 297-302.

[2] Li, X., Cai, Z., Winandy, J. E. and Basta, A. H. 2010. "Selected Properties of Particleboard Panels Manufactured from Rice Straws of Different Geometries.” Bioresource Technology 101: 4662-6.

[3] Ciannamea, E. M., Stefani, P. M. and Ruseckaite, R. A. 2010. "Medium-Density Particleboards from Modified Rice Husks and Soybean Protein Concentrate-Based Adhesives.” Bioresource Technology 101: 818-25.

[4] Tabarsa, T., Ashori, A. and Gholamzadeh, M. 2011. "Evaluation of Surface Roughness and Mechanical Properties of Particleboard Panels Made from Bagasse.” Composites Part B 42: 1330-5.

[5] Pirayesh, H., Khanjanzadeh, H. and Salari, A. 2013. "Effect of Using Walnut/Almond Shells on the Physical, Mechanical Properties and Formaldehyde Emission of Particleboard.” Composites Part B 45: 858-63.

[6] Saari, N., Hashim, R., Sulaiman, O., Hiziroglu, S., Sato, M. and Sugimoto, T. 2014. "Properties of Stream Treated Binderless Particleboard Made from Oil Palm Trunks.” Composites Part B 56: 344-9.

[7] "Monthly Statistics OF Agriculture, Forestry and Fisheries, 11 Nov. 2014.” Accessed Dec. 24, 2014. http://www.maff.go.jp/e/tokei/kikaku/monthly_e/pdf/gall. pdf.

[8] Ndazi, B. S., Karlsson, S., Tesha, J. V. and Nyahumwa, C. W. 2007. "Chemical and Physical Modification of Rice Husks for Use as Composite Panels.” Composites Part A 38: 925-35.

[9] JIS-A 5908. 2003. "Particleboards. Japanese Standard Association.” Tokyo, Japan. 1-24. 